\title{
Determinants of Use of Skilled Birth Attendance among Mothers Who Gave Birth in the Past 12 months in Raya Alamata District, North East Ethiopia
}

Fentaw Tadese* and Ahmed Ali

Department of Public Health, Debre Markos University, Ethiopia

*Corresponding author: Fentaw Tadese, Lecturer, Department of Public Health, Debre Markos University, Debre Markos, Ethiopia, Tel: +251920300321; Fax: +251587711764; E-mail: fentadese760@yahoo.com

Received date: June 02, 2014, Accepted date: October 29, 2014, Published date: November 07, 2014

Copyright: ( 2014 Tadese F, et al. This is an open-access article distributed under the terms of the Creative Commons Attribution License, which permits unrestricted use, distribution, and reproduction in any medium, provided the original author and source are credited.

\begin{abstract}
Background: A large number of women are dying due to factors related to pregnancy and childbirth, especially in developing countries including Ethiopia, where maternal mortality ratio is one of the highest in the world. It is known that having a skilled birth attendant at every

delivery can lead to marked reductions in maternal mortality. In Ethiopia, most births take place at home, particularly in rural areas, being not attended by a skilled birth attendant. The utilization of maternal health services is a complex phenomenon and it is influenced by several factors.
\end{abstract}

Objectives: This study assessed factors that determine the utilization of skilled birth attendants among mothers who gave birth in the past 12 months in Raya Alamata District, Ethiopia.

Methods: Community-based cross sectional study was conducted among mothers who gave birth in the past 12 months. A total of 600 study participants were recruited for the study. Logistic regression was performed using SPSS version 16.0 software and thematic interpretation based on main categories was done for the qualitative data.

Results: A total of 584 mothers (189 urban and 395 rural) were included in the analysis. Only $23.5 \%$ of births were attended by Skilled Birth Attendants. Over $43 \%$ of urban women delivered with skilled assistance compared to $13.9 \%$ of rural women. In multivariate analysis urban residence, Age at interview, maternal formal education, Ante Natal Care visit during the last pregnancy, joint final decision making, knowledgeable and favorable attitude towards danger signs of pregnancy, child birth and delivery services were most significant determinants of skilled birth attendant use by mother.

Conclusion and recommendation: Utilization of skilled delivery attendance services was still low with a high number of deliveries being attended by unqualified persons at home. Promotion of universal Ante Natal Care followup and encouragement of mothers regarding the need for Skilled Birth Attendants during childbirth is of paramount importance.

Keywords: Skilled birth attendant; Maternal mortality

\section{Introduction}

Maternal mortality remains a major challenge to health systems of developing countries. Globally, an estimated 287,000 maternal deaths occurred in 2010, a decline of $47 \%$ from levels in 1990. Sub-Saharan Africa and Southern Asia accounted for $85 \%$ of the global burden of maternal deaths with sub-Saharan Africa alone accounting for $56 \%$ in 2010 [1]. Nearly two third of maternal deaths worldwide are due to five direct causes: Obstetric hemorrhage is the main direct cause accounting for $25 \%$ of maternal deaths, infections (15\%), unsafe abortion (13\%), eclampsia (12\%), and obstructed labor (8\%) [2].

Based on the available empirical evidence, facility based delivery at primary level, backed by access to referral-level facilities is a priority strategy for reducing maternal mortality [3]. In an effort to reduce maternal mortality, the indicators of progress are Maternal Mortality Ratio and proportion of births attended by skilled attendants [4]. The fifth MDG aims at improving maternal health and targets reducing Maternal Mortality Ratio by 75\% between 1990 and 2015 - that is, it seeks to achieve an expected 5.5\% annual decline in MMR from 1990 [1]. The recently released 2011 EDHS reported MMR of 676 per 100,000 which is a slight increase from the 2005 DHS which was MMR of 673 per $100,000[5,6]$.

In almost all countries where health professionals attend more than $80 \%$ of deliveries, MMR is below 200 per 100,000 live births [7]. Skilled attendance during labor, delivery and the early post-partum period could reduce an estimated 16 to 33 percent of deaths due to obstructed labor, haemorrhage, sepsis and eclampsia [8]. Maternal health care utilization is highly varies as a function of women's background characteristics as reported by different studies. Of these; educational status, place of residence, socio-economic, age has been found to have the strongest association with the use of maternal skilled birth attendant [5,9-15].

In addition mother's knowledge and attitude towards delivery services as well as ANC visit during last pregnancy were also other important predictor factors $[14,16]$. Other important determinants of utilization of delivery care services were parity, history of prolonged labor and women's decision-making power as well as distance and 
transport [17-20]. According to the EDHS 2011, 57\% of births were assisted by a relative, or some other person. $28 \%$ of births were assisted by a traditional birth attendant, while $4 \%$ of births were delivered without any type of assistance [5].

Hence, the objective of the study was assessing and understanding the factors that determine the utilization of skilled birth attendant. Assessing institutional service delivery among women across all geographical regions is crucial to enhance maternal health and improve the maternity services and thereby reduce maternal mortality given that the slow decline in the risk of maternal death in Ethiopia.

\section{Methodology}

\section{Study area and design}

The study area was Raya Alamata District which is found $600 \mathrm{~km}$ away from Addis Ababa. The District had four urban kebeles and 15 rural tabias. Its population was estimated to be 141,695 based on census 2007. Regarding the health infrastructure, the district had one district hospital, six health centers and 13 health posts [21]. Community based cross-sectional study design was employed to assess the determinants of utilization of skilled birth attendant.

\section{Source and study population}

All women in the reproductive age group (15-49 years) in Alamata District constituted the source population. Women who had given birth in the last 12 months, irrespective of the outcome of the birth were included for the study.

\section{Sample size and sampling procedures}

Sample size was determined using a formula for two population proportions by taking the level of significance to be $5 \%$ and the power $80 \%$.

To determine the sample size, the following assumptions were considered.

Place of residence was considered as predictor factor for use of skilled birth attendant. Women were categorized into Urban and Rural [15].

$\mathrm{P}_{1}=$ Proportion of urban resident women who delivered by skilled birth attendant $=22.4 \%$

$\mathrm{P}_{2}=$ Proportion of rural resident women who delivered by skilled birth attendant $=10.7 \%$

$\mathrm{r}=$ ratio of $\mathrm{n}_{1}$ to $\mathrm{n}_{2}$ considered to be $1: 2$ and Confidence level=95\%

Based on the above assumptions design effect of 1.5 and $5 \%$ nonresponse rate, 600 women who gave delivery in the past 12 months were requited. Using proportional allocation to the Rural and Urban; 400 samples were from rural kebeles and 200 samples from urban residents.

\section{Sampling procedures}

Multi-stage stratified sampling method with probability proportionate-to-size was employed. First, the District was stratified into four urban kebeles and 15 rural Tabias; two from urban kebeles and four from the rural tabias were chosen by lottery method. The final sampling units were households with at least one birth in the 12 months preceding the survey. Out of the four sampled rural Tabias, a total of 400 samples were selected; of those, 103 from Tao, 108 from Selenwuha, 57 from Kulugeze Lemlem and 132 from Timuga. From the two sampled urban kebeles, a total of 200 women; 94 for kebele 02 and 106 for kebele 04 were allocated. Finally, Systematic sampling method was applied to select study participants (Figure 1).

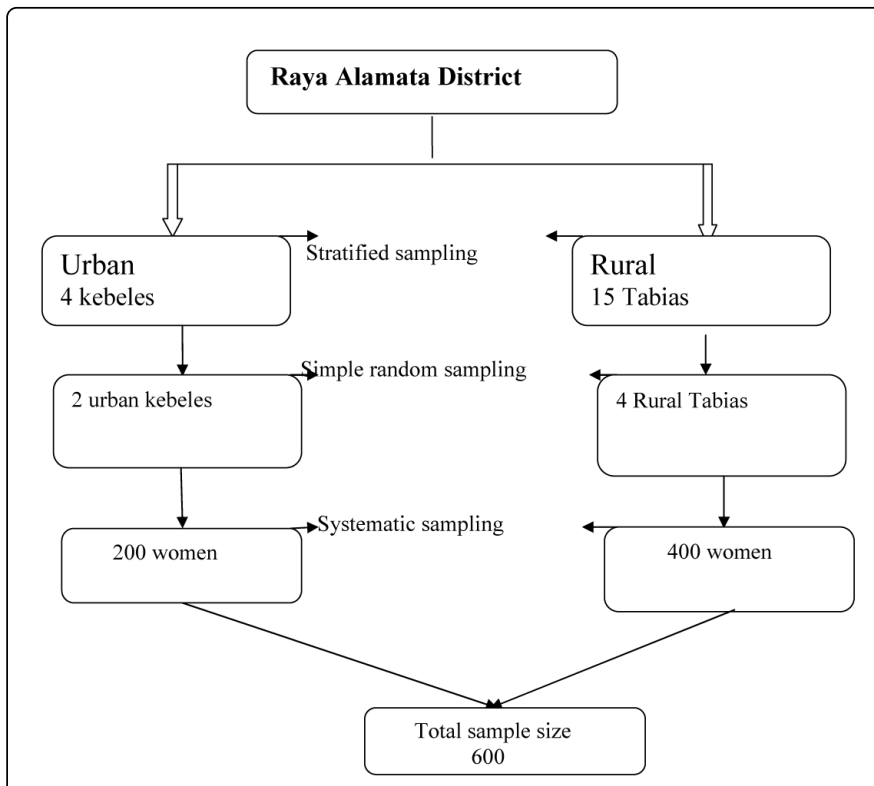

Figure 1: Schematic presentation of sampling frame for the study.

Independent variables include socioeconomic and demographic factors such as age, education, occupation, income, obstetric factors such as parity, history of stillbirth, ANC follow up and knowledge and attitude on key danger signs of pregnancy, labor/childbirth and delivery services. The dependent variable was use of Skilled Birth Attendant.

\section{Data collection procedures}

Data were collected through face-to-face interview using pre-tested structured questionnaire developed in English after reviewing relevant literatures. The questionnaire was translated into the local language, and to check for its consistency, back translated into English. Five data collectors were used to conduct the face-to-face interview and data collection process was supervised by one health officer and the Principal Investigator. Training was given to the data collectors and supervisors before the actual data collection regarding the aim of the study, data collection tool and procedures going through the questionnaires question by question.

\section{Data quality management}

The data collection tool was pre-tested on 15 similar women in the study area from randomly selected kebeles and tabias which were not included in the study before the initiation of the main study. Findings and experiences from the pre-test were utilized in modifying the data collection tool. Supervision was conducted by the Principal Investigator and Supervisor. Each questionnaire was given a unique code and was entered using Epi-info version 3.5.1. Then, the entered data were cleaned for errors prior to data analysis. Frequencies were used to check for missed values and outliers during analysis. Any 
Page 3 of 9

errors identified were corrected after revision of the original data using the code numbers given to the questionnaires.

\section{Data analysis procedures}

Data were cleaned for inconsistencies and missing values and analyzed using SPSS version 16.0 statistical software. Frequencies and Proportions were computed for description of the study population. Significance was determined using crude and adjusted odds ratios with 95\% confidence intervals. First bivariate relationships between each independent variable and outcome were investigated using binary logistic regression model. Those independent variables found to be significant with $\mathrm{p}$-value less than 0.05 at the bivariate level were included in a multivariate logistic regression model for each dependent variable to control for potential confounding variables. The results were presented in the form of tables, figures and summary statistics.

\section{Operational definitions}

Skilled attendant: is a professionally trained health worker having the essential midwifery skills to manage normal labour and delivery, recognize complications early and perform any essential interventions including early referral.

Reinforcing factors: are influences of people that encourage or discourage behavioral change.

Formal education: consists of primary, secondary and above educational attainment of respondents.

Non-formal education: consists of unable to read and write, read and write only educational attainment of respondents

Knowledgeable: women were considered knowledgeable if they were aware of danger signs related to pregnancy and childbirth and advantages of delivery service, and use SBA if they scored above median of knowledge questions, and not knowledgeable if otherwise.

Favourable attitude: women were considered as having favorable attitude towards danger signs related to pregnancy and childbirth and advantages of delivery service, and use SBA if they scored above the median on attitude questions, and unfavourable if otherwise.

\section{Ethical consideration}

The proposal was approved by the Addis Ababa University, School of Public Health, and the College of Health Science Institutional Ethical Review Board. An official letter was written from the School of Public Health to Tigray Regional Health Bureau and Alamata Woreda Health and Administrative Offices to seek the essential cooperation. During data collection, individual informed verbal consent was obtained and each respondent was informed about the objective of the study, procedures of selection and assurance of confidentiality.

\section{Results}

\section{Socio-demographic characteristics of the respondents}

The majority of the respondents were in the age range of 25-34 years (47.6\%) making the mean age of (Standard deviation [SD]) 28.8 $( \pm 7)$ years. Out of the total respondents, 455 (77.9\%) were Orthodox Christian, married 570 (97.6\%), unable to read and write 316 (54.1), housewives $511(87.5 \%)$ while $444(76 \%)$ of the husbands were farmers. Two hundred thirty nine $(40.9 \%)$ households had average monthly expenditure of between 501-999 ETB (Table 1).

\begin{tabular}{|c|c|c|c|}
\hline \multirow[t]{2}{*}{ Variables } & \multirow[t]{2}{*}{ Categories } & \multicolumn{2}{|c|}{ Total $(n=584)$} \\
\hline & & $\mathbf{n}$ & $\%$ \\
\hline \multirow[t]{3}{*}{ Age (years) } & $15-24$ & 158 & 27.1 \\
\hline & $25-34$ & 278 & 47.6 \\
\hline & 35 and above & 148 & 25.3 \\
\hline \multirow[t]{2}{*}{ Ethnicity } & Tigre & 539 & 92.3 \\
\hline & Amhara/Others $\dagger$ & 45 & 7.7 \\
\hline \multirow[t]{3}{*}{ Religion } & Orthodox & 455 & 77.9 \\
\hline & Muslim & 115 & 19.7 \\
\hline & Protestant & 14 & 2.4 \\
\hline \multirow[t]{2}{*}{ Marital status } & Married & 570 & 97.6 \\
\hline & Single/divorced/widow & 14 & 2.4 \\
\hline \multirow{4}{*}{$\begin{array}{l}\text { Mother's } \\
\text { educational } \\
\text { status }\end{array}$} & Unable to read and write & 245 & 42 \\
\hline & Read and write only & 188 & 32.2 \\
\hline & Primary education & 102 & 17.5 \\
\hline & Secondary and above & 49 & 8.4 \\
\hline \multirow{4}{*}{$\begin{array}{l}\text { Husband's } \\
\text { educational } \\
\text { status }\end{array}$} & Unable to read and write & 245 & 42 \\
\hline & Read and write only & 188 & 32.2 \\
\hline & Primary education & 102 & 17.5 \\
\hline & Secondary and above & 49 & 8.4 \\
\hline \multirow{3}{*}{$\begin{array}{l}\text { Mother's } \\
\text { occupational } \\
\text { status }\end{array}$} & House wife & 511 & 87.5 \\
\hline & Government employee & 28 & 4.8 \\
\hline & Merchant/Others* & 45 & 7.2 \\
\hline \multirow{3}{*}{$\begin{array}{l}\text { Husband } \\
\text { Occupational } \\
\text { status }\end{array}$} & Farmer & 444 & 76 \\
\hline & Employed ${ }^{* *}$ & 47 & 8 \\
\hline & Merchant/Others ${ }^{\star * *}$ & 93 & 15.9 \\
\hline \multirow{3}{*}{$\begin{array}{l}\text { Mass media } \\
\text { possession }\end{array}$} & Radio & 233 & 39.9 \\
\hline & Television & 122 & 20.9 \\
\hline & Mobile phone & 332 & 56.8 \\
\hline \multirow{2}{*}{$\begin{array}{l}\text { Time taken to } \\
\text { nearby HF }\end{array}$} & $\leq 30$ minute & 298 & 51 \\
\hline & $>30$ minute & 286 & 49 \\
\hline \multirow{4}{*}{$\begin{array}{l}\text { Monthly } \\
\text { average } \\
\text { expenditure }\end{array}$} & $\leq 500$ ETB & 55 & 9.4 \\
\hline & 501-999 ЕТВ & 239 & 40.9 \\
\hline & 1000-1499 ЕТВ & 182 & 31.2 \\
\hline & $\geq 1500$ ETB & 108 & 18.5 \\
\hline
\end{tabular}


Page 4 of 9

${ }^{\star * *}$ Others (Daily Labour, Unemployed); ${ }^{* *}$ Employed (Governmental and Private); *Others (Daily Labour, Private Employee); †(Oromo, Gamo); HF: Health Facility; ETB: Ethiopian Birr

Table 1: Socio demographic characteristics of the study participants, Alamata District, North East Ethiopia, 2013 ( $\mathrm{n}=584)$.

\section{Past obstetric characteristics of the respondents}

Regarding age at first marriage $354(60.7 \%)$ of the study subjects were married before the age of eighteen. Four hundred thirty $(73.6 \%)$ respondents were first pregnant before the age of 20 years. The mean parity of participants was 3.4. In this study, 536 (91.8\%) women reported that their last pregnancy was planned and 520 (89.1) of respondents said that there was preparation for the last delivery. Out of the total respondents, 51 (9\%) had history of abortion and stillbirth 40 (7.1\%). Regarding the prenatal service utilization of the respondents, 338 (57.9\%) had attended ANC service. Among those women who attended ANC the majority, 149 (44.1\%) respondents had ANC visits of four and above (Table 2).

\begin{tabular}{|c|c|c|}
\hline \multirow{2}{*}{ Variables } & \multicolumn{2}{|c|}{ Total $(n=584)$} \\
\hline & $\mathbf{N}$ & $\%$ \\
\hline \multicolumn{3}{|c|}{ Age at first marriage } \\
\hline$<18 y$ rs & 354 & 60.6 \\
\hline 18 yrs \& above & 230 & 39.4 \\
\hline \multicolumn{3}{|c|}{ Age at first Pregnancy } \\
\hline$<20$ yrs & 430 & 73.6 \\
\hline 20 yrs \& above & 154 & 26.4 \\
\hline \multicolumn{3}{|l|}{ Parity } \\
\hline 1 & 124 & 21.2 \\
\hline 4-Feb & 296 & 50.7 \\
\hline$\geq 5$ & 164 & 28.1 \\
\hline \multicolumn{3}{|c|}{ Ever had history of abortion } \\
\hline Yes & 53 & 9.1 \\
\hline No & 531 & 90.9 \\
\hline \multicolumn{3}{|c|}{ Ever had history of still birth } \\
\hline Yes & 41 & 7 \\
\hline No & 543 & 93 \\
\hline \multicolumn{3}{|c|}{ Last pregnancy planned } \\
\hline Yes & 536 & 91.8 \\
\hline No & 48 & 8.2 \\
\hline \multicolumn{3}{|c|}{ ANC visit during last pregnancy } \\
\hline Yes & 338 & 57.9 \\
\hline
\end{tabular}

\begin{tabular}{|c|c|c|}
\hline No & 246 & 42.1 \\
\hline \multicolumn{3}{|c|}{ ANC frequency $(n=338)$} \\
\hline one & 46 & 13.6 \\
\hline Two to three & 143 & 42.3 \\
\hline Four and above & 149 & 44.1 \\
\hline \multicolumn{3}{|c|}{ PNC visit after last delivery } \\
\hline Yes & 88 & 15.1 \\
\hline No & 496 & 84.9 \\
\hline \multicolumn{3}{|c|}{ Experience adverse pregnancy outcome } \\
\hline Yes & 76 & 16 \\
\hline No & 398 & 84 \\
\hline
\end{tabular}

Table 2: Obstetric characteristics of respondents in Alamata District, North East Ethiopia, 2013.

Seventy five of the respondents experienced at least one adverse pregnancy and child birth outcome previously (Table 2). Among the problems mentioned were bleeding $35(46.7 \%)$, prolonged labor 26 $(34.7 \%)$, retained placenta $21(28 \%)$ and others $7(9.3 \%)$. Out of the total study subjects $69(17.5 \%)$ rural and $19(10.1 \%)$ urban had visited health facility for postnatal natal care (Table 2). Reasons for PNC visit were bleeding $25(28.4 \%)$, retained placenta $22(25 \%)$, puerperal sepsis 11 (12.5\%), breast problems $11(12.5 \%)$ and others including immunization and family planning 25 (28.4\%).

\section{Institutional delivery service utilization}

Regarding institutional delivery service utilization, 137 (23.5\%) of the women gave their last birth at health institutions being attended by skilled birth attendant [Urban 82 (43.4\%), 55 (13.9\%) of the rural]. The majority of rural study subjects $340(86.1 \%)$ delivered at home without assistance from skilled birth attendant compared.

The majority of the respondents gave reasons for institutional delivery, $110(80.3 \%)$ safe for the mother and child, 83 (60.6\%) better outcomes from institutional delivery. The respondents also reported that delivery at health institution lowers maternal exhaustion, facilitate the progress of labor by giving medication and avoid excessive bleeding which all are classified under others 8 (5.8\%) (Figure 2).

Among the mothers who delivered at home, 396 (88.6\%) were assisted by family members and mothers, untrained TBAs 91 (20.4\%) and no one or without any assistance 18 (3.1\%). Mothers gave a variety of reasons for delivering at home. Of these, having closer attention from family members and relatives 327 (73.2\%), feel more comfortable $269(60.2 \%)$, urgent and smooth labor 256 (57.3\%), delivering at home is my usual experience 118 (26.4\%), were among fthe commonest (Figure 3). 
Citation: Tadese F, Ali A (2014) Determinants of Use of Skilled Birth Attendance among Mothers Who Gave Birth in the Past 12 months in Raya Alamata District, North East Ethiopia. Clinics Mother Child Health 11: 164. doi:10.4172/2090-7214.1000164

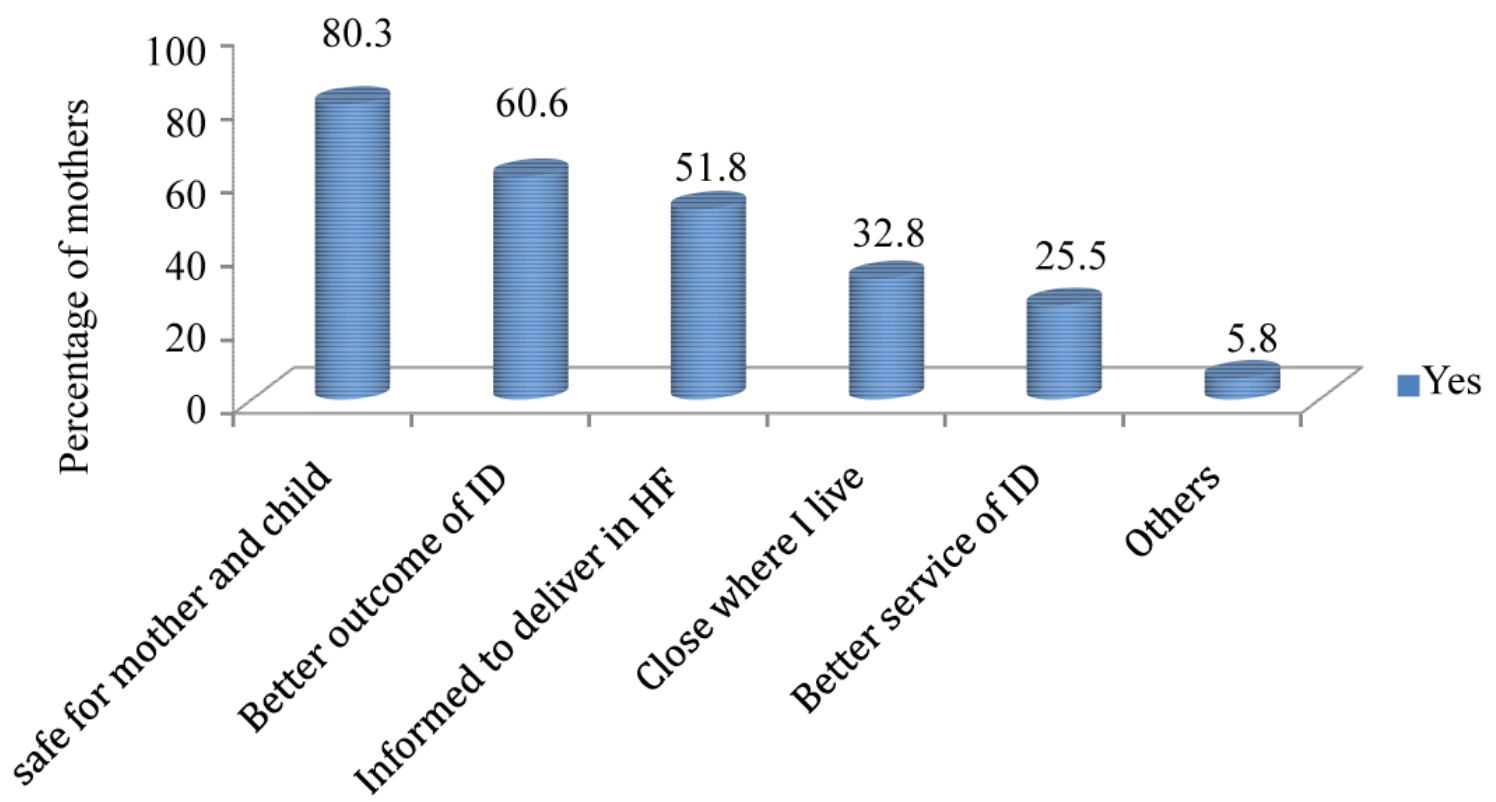

Figure 2: Reasons for skilled birth attendant during delivery among study subjects in Alamata District, North East Ethiopia, 2013. ID: Institutional Delivery; HF: Health Facility.

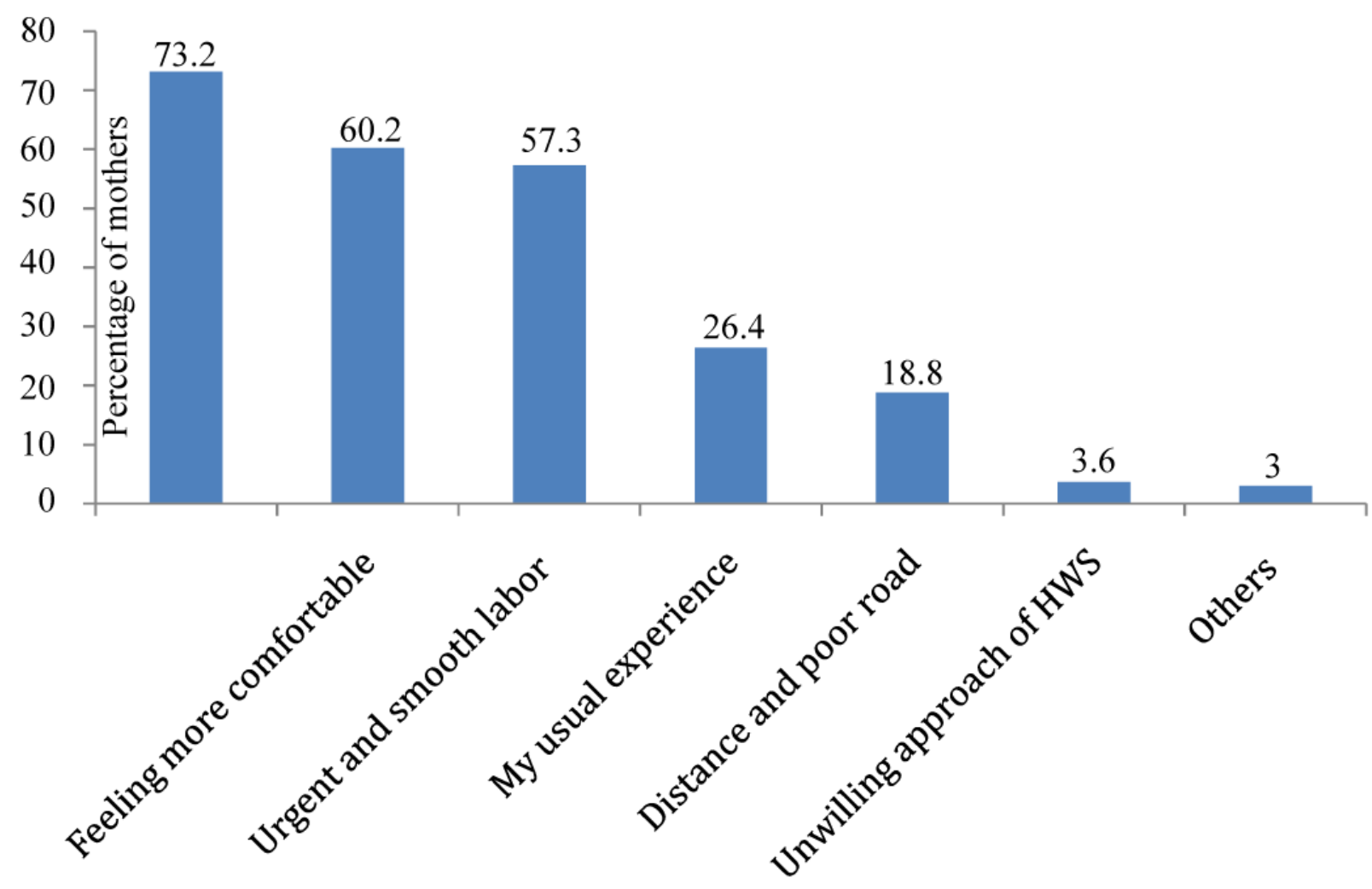

Figure 3: Reasons for home delivery among study subjects in Alamata District, North East Ethiopia, 2013. 
Citation: Tadese F, Ali A (2014) Determinants of Use of Skilled Birth Attendance among Mothers Who Gave Birth in the Past 12 months in Raya Alamata District, North East Ethiopia. Clinics Mother Child Health 11: 164. doi:10.4172/2090-7214.1000164

Page 6 of 9

\section{Knowledge and attitude about pregnancy, labor and delivery} service

One hundred eight $(57.1 \%)$ of urban and $193(48.9 \%)$ of rural mothers scored more than the mean score on knowledge questions of danger signs related to pregnancy, labor and child birth, and also on advantages of delivery service. On the other hand, their attitudes towards danger signs of pregnancy, child birth and safe delivery service utilization, $154(81.5 \%)$ urban and $282(62.8 \%)$ rural study subjects showed favorable attitudes towards pregnancy, child birth and safe delivery service utilization (Table 3 ).

\begin{tabular}{|l|l|l|l|}
\hline Variable & $\begin{array}{l}\text { Rural }(\mathbf{n = 3 9 5 )} \\
\mathbf{n}(\%)\end{array}$ & $\begin{array}{l}\text { Urban(n=189) } \\
\mathbf{n}(\%)\end{array}$ & $\begin{array}{l}\text { Total (n=584) } \\
\mathbf{n}(\%)\end{array}$ \\
\hline General knowledge on danger of obstetrics problems & \multicolumn{2}{|l|}{} \\
\hline Not Knowledgeable & $202(51.1)$ & $81(42.9)$ & $283(48.5)$ \\
\hline Knowledgeable & $193(48.9)$ & $108(57.1)$ & $301(51.5)$ \\
\hline Respondents attitude on danger signs and delivery services & & \\
\hline Unfavorable & $147(37.2)$ & $35(18.5)$ & $182(31.2)$ \\
\hline Favorable & $248(62.8)$ & $154(81.5)$ & $402(68.8)$ \\
\hline
\end{tabular}

Table 3: Overall knowledge and attitude of the respondents by residential area among mothers in Alamata District, North East Ethiopia, 2013.

Mothers who live in urban were 2.2 times more likely to be assisted by skilled birth attendant during delivery $(\mathrm{AOR}=2.2,95 \% \mathrm{CI} ; 1.2-4.1)$. Mothers in 15-24 years age group during the interview were 3.7 times (AOR=3.7, 95\% CI: 1.3-7.4) more likely to be assisted by skilled birth attendant than mothers more than 35 and above. Mothers with formal education $(\mathrm{AOR}=5.3,95 \% \mathrm{CI}=2.9-9.8)$ had a 5.3 times higher to be attended by skilled birth assistants than those who had no formal education (Table 4).

\begin{tabular}{|c|c|c|c|c|c|}
\hline \multicolumn{2}{|l|}{ Variables } & \multicolumn{2}{|c|}{ Skilled birth attendant } & \multirow{3}{*}{$\begin{array}{l}\text { COR }(95 \% \mathrm{Cl}) \\
1\end{array}$} & \multirow{3}{*}{$\begin{array}{l}\text { AOR } 95 \% \mathrm{Cl} \\
1\end{array}$} \\
\hline & & \multirow{2}{*}{$\begin{array}{l}\text { Yes } \\
55\end{array}$} & \multirow{2}{*}{$\begin{array}{l}\text { No } \\
340\end{array}$} & & \\
\hline Residence & Rural & & & & \\
\hline & Urban & 82 & 107 & $4.7(3.2-7.1)^{\star * \star}$ & $2.2(1.2-4.1)^{*}$ \\
\hline \multirow[t]{3}{*}{ Age at interview } & $15-24$ & 54 & 104 & $5.4(2.8-10.4) * * \star$ & $3.7(1.3-10.3)$ * \\
\hline & $25-34$ & 70 & 208 & $3.5(1.9-6.6)$ & $3.1(1.3-7.4)$ * \\
\hline & 35 and above & 13 & 135 & 1 & 1 \\
\hline \multirow[t]{2}{*}{ Maternal education } & No formal education & 53 & 373 & 1 & 1 \\
\hline & Formal education & 84 & 74 & $7.98(5.2-12.2) * * *$ & $5.3(2.9-9.8) * \star *$ \\
\hline \multirow[t]{2}{*}{ Husband education } & No formal education & 68 & 365 & 1 & 1 \\
\hline & Formal education & 69 & 82 & $4.5(2.9-6.8) * * *$ & $1.4(0.8-2.6)$ \\
\hline \multirow[t]{2}{*}{ Maternal occupation } & Housewife & 102 & 409 & 1 & 1 \\
\hline & Governmental/others & 35 & 38 & $3.7(2.2-6.1)^{\star * \star}$ & $0.6(0.3-1.4)$ \\
\hline \multirow{2}{*}{$\begin{array}{l}\text { Time taken to nearby } \\
\text { health facility }\end{array}$} & $\leq 30$ minute & 103 & 195 & $3.9(2.5-6.0)$ & $1.6(0.9-3.1)$ \\
\hline & $>30$ minute & 34 & 252 & 1 & 1 \\
\hline \multirow[t]{4}{*}{ Monthly expenditure } & $\leq 500$ & 12 & 43 & 1 & 1 \\
\hline & $501-999$ & 37 & 202 & $0.7(0.3-1.5)$ & $0.9(0.4-2.2)$ \\
\hline & $1000-1499$ & 47 & 135 & $1.3(0.6-2.7)$ & $1.4(0.5-3.5)$ \\
\hline & $\geq 1500$ & 41 & 67 & $2.2(1.04-4.6)$ * & $2.3(0.4-6.3)$ \\
\hline Age at first pregnancy & $<20$ years & 90 & 340 & 1 & 1 \\
\hline
\end{tabular}




\begin{tabular}{|c|c|c|c|c|c|}
\hline & $\geq 20$ years & 47 & 107 & $1.7(1.1-2.5)$ *** & $1.1(0.6-2.1)$ \\
\hline \multirow[t]{2}{*}{ Parity } & $1-3$ & 112 & 223 & $4.5(2.8-7.2)$ ** & $1.4(0.7-2.99)$ \\
\hline & 4 and above & 25 & 224 & 1 & 1 \\
\hline \multirow[t]{2}{*}{ ANC visit } & Yes & 120 & 218 & $7.4(4.3-12.7)^{* * *}$ & $3.4(1.8-6.5)^{* * \star}$ \\
\hline & No & 17 & 229 & 1 & 1 \\
\hline \multirow{2}{*}{$\begin{array}{l}\text { Knowledge about obstetric } \\
\text { complications }\end{array}$} & Knowledgeable & 103 & 198 & $3.8(2.5-5.9) * * *$ & $3.3(1.9-5.7)^{\star \star \star}$ \\
\hline & Not knowledgeable & 34 & 249 & 1 & 1 \\
\hline \multirow[t]{2}{*}{ Attitude of respondents } & Favorable & 116 & 286 & $3.1(1.9-5.1)^{* * *}$ & $2.3(1.2-4.5) * *$ \\
\hline & Favorable & 21 & 161 & 1 & 1 \\
\hline \multirow[t]{3}{*}{ Who decides } & Myself & 25 & 176 & 1 & 1 \\
\hline & Husband/others & 11 & 58 & $1.3(0.6-2.9)$ & $1.3(0.3-3.4)$ \\
\hline & Both of us & 101 & 213 & $3.3(2.1-5.4) * * *$ & $3.2(1.7-6.0) * \star \star$ \\
\hline
\end{tabular}

Table 4: Determinants of the use of SBAs among women who gave birth in the past 12 months in Alamata District, Northeast Ethiopia, 2013 $(\mathrm{n}=584)$.

Mothers who had ANC visit were 3.4 times more likely to be assisted by skilled birth attendants than women who did not have ANC visit in the district ( $\mathrm{AOR}=3.4,95 \% \mathrm{CI}=1.8-6.5)$. In addition, mothers who were knowledgeable and having favorable attitude were 4.7 (AOR=4.7 95\% CI: 2.1-10.5) and 3.3 (AOR=3.3, 95\% CI: 1.2-8.9) respectively times more likely to be attended by skilled birth attendants in rural areas (Table 4).

Regarding final decision making about place of delivery; mothers who decided jointly were 3.2 times more higher of utilizing of skilled birth attendants during delivery when compared to self-decision making in the district (AOR=3.2, 95\% CI: 1.7-6.0) (Table 4).

\section{Discussion}

The results of the study revealed that the proportion of women who delivered with assistance of skilled birth attendant was $23.5 \%$ in the District. This result is in line with that of a study done Ephratanagidim District, North Shoa zone which was $21.4 \%$ [22]. However, it was higher than Tigray Region EDHS result of 2011 which were 11.6\% [5]. This might be improvements in accessing and utilizing of the service and community mobilization through developmental army. On the other hand, it was lower than those studies conducted in central Tanzania and India where the proportion of women who gave birth at health facilities was $54 \%$ and $49.8 \%$, respectively [23,24]. The difference could be explained by the fact that women in those countries had better economic status, educational status and ANC service.

There was a statistically significant association between place of residence and use of skilled birth attendant. The result revealed that urban women were more likely to give birth assisted by skilled birth attendants at delivery. This finding was in agreement with previous studies conducted in other areas of the country [14-16] and elsewhere $[12,25]$. This might be due to the fact that urban women tend to have advantage from increased knowledge and access to delivery service.
Health promotion mass media programs are urban-focused compared to the rural counterparts. On the other hand their rural counterparts are mostly influenced by traditional practices [17].

Younger women were more likely to give birth assisted by skilled birth attendants than those with age of 35 years and above. This finding is in agreement with studies done in other areas of the country $[17,26]$. When younger women are just starting child bearing, they are told to be in a high risk group and so they tend to fear home deliveries. On the contrary, older women consider that giving birth at home is not risky as they had experienced previously. It is also higher proportion of younger women had formal education which in turn had different perspectives on delivery care when compared to the elder.

Among social factors women's education was statistically and positively related to the use of skilled birth attendants during delivery. Again, the finding was consistent with other studies done in other areas of the country $[15,16,26]$ and elsewhere $[9,23]$. This may be due to the fact that educated women are more likely to make wise decisions about their own health and seek proper health care than their counterparts.

The study also revealed a significant association between ANC visit during last pregnancy of the women and the use of skilled assistance during delivery. Women who had ANC visit were 3.4 times higher odds of delivering with assistance by health professionals than mothers who didn't visit ANC. The result was in line with other studies done $[9,13]$. It is fact that women having ANC visit are provided with health education and information regarding the benefits of having a skilled birth attendant during childbirth.

Women who had knowledge regarding pregnancy and delivery risk factors were more likely to give birth assisted by skilled birth attendant during delivery. Similar findings were reported in other parts of the county and Sub-Saharan African countries [14,27]. Women's positive attitude towards danger signs related to pregnancy and childbirth was 
also important predictor for the utilization of skilled birth assistant This finding was in agreement with a study done in Arsi zone, South East Ethiopia [16]. This might mean that better informed individual is better placed to make reasonable decisions.

The patterns of decision making power within the household were perceived as key determinants of place of delivery. The study showed that joint decision making had significant association with use of skilled birth attendant during delivery. The finding is in agreement with study done in Uganda [28]. More than two third were assisted by family members and mothers, followed by untrained traditional birth attendant. This finding was consistent with Tigray Region EDHS 2011 and studies done in other parts of the country [5,14]. This might be due to the trust on the family or the relatives in giving support, close attention and fulfilling different cultural and religious ceremonies.

Concerning reasons for home delivery preference the finding revealed that having closer attention from family members, feel more comfortable, delivering at home being the women's experience, and distance and poor road were the commonest reasons. This finding is in agreement with studies done in North Gonder, Arsi Zone and South East Ethiopia $[10,15,16]$. This implies significant proportions of women may seek help from skilled birth attendants after encountering obstetric complications and when other traditional interventions fail.

In conclusion, utilization of skilled delivery attendance services was low with a high number of deliveries being attended by unqualified persons at home. Women's education, place of residence, having ANC visit, age at interview, final decision maker and knowledge and attitude towards pregnancy, child birth and delivery services were found to be determinants of skilled birth attendance. Promote universal ANC follow-up and encourage mothers to utilize skilled birth attendants during pregnancy and childbirth. Increase the number of ambulance or vehicle for referral of the women with obstetric complication to the nearest possible health facilities with Comprehensive Emergency Obstetrics Cares. Design different means of behavioral change communication to improve the demand. Moreover, to explore further factors related with the use of skilled assistance at delivery qualitative studies need to be conducted.

\section{Acknowledgement}

My special thanks go to UNFPA for sponsoring the study. I would like to thank Addis Ababa University, School of Public Health and Raya Alamata Health and Administrative offices for their cooperation to the successful accomplishment of this research project. Finally, I would like to acknowledge the study subjects who have kindly cooperated in providing the required information.

\section{References}

1. WHO, UNFPA, UNICEF, World Bank (2012) Trends in Maternal mortality from 1990 to 2010. Geneva, Switzerland.

2. Ronsmans C, Graham WJ; Lancet Maternal Survival Series steering group (2006) Maternal mortality: who, when, where, and why. Lancet 368: 1189-1200.

3. Campbell OM, Graham WJ; Lancet Maternal Survival Series steering group (2006) Strategies for reducing maternal mortality: getting on with what works. Lancet 368: 1284-1299.

4. UN (2007) The Millennium Development Goals report: Statistical annex New York.

5. Central Statistical Agency [Ethiopia], ICF International (2012) Ethiopia Demographic and Health Survey 2011. Addis Ababa, Ethiopia and
Calverton, Maryland, USA: Central Statistical Agency and ICF International.

6. Central Statistical Agency [Ethiopia], Macro ORC (2006) Ethiopia Demographic and Health Survey 2005. Addis Ababa, Ethiopia and Calverton, Maryland, USA: Central Statistical Agency and ORC Macro.

7. UNFPA (2004) Maternal Mortality updates: Delivering in to good hands.

8. Graham W, Bell JS, Bullough HW (2001) Can Skilled Attendance at Delivery Reduce Maternal Mortality in Developing Countries?

9. Agha S, Carton TW (2011) Determinants of institutional delivery in rural Jhang, Pakistan. Int J Equity Health 10: 31.

10. Mesfin N, Damen H, Getnet M (2004) Assessment of Safe Delivery Service Utilization among women of child bearing age in North Gondar Zone. Ethiop J Health Dev 18: 146-150.

11. Wagle RR, Sabroe S, Nielsen BB (2004) Socioeconomic and physical distance to the maternity hospital as predictors for place of delivery: an observation study from Nepal. BMC Pregnancy Childbirth 4:8.

12. Mohammad A, Kabir (2007) Safe-delivery practices in rural Bangladesh and its associated factors: evidence from Bangladesh demographic and health survey-2004. East African Journal of Public Heath 4: 67-72.

13. Babalola S, Fatusi A (2009) Determinants of use of maternal health services in Nigeria--looking beyond individual and household factors. BMC Pregnancy Childbirth 9: 43.

14. Alemayehu S, Fekadu M, Solomon M (2010) Institutional delivery service utilization and associated factors among mothers who gave birth in the last 12 months in Sekela District, North West of Ethiopia: A community based cross sectional study. BMC Pregnancy Childbirth 12: 74 .

15. Amano A, Gebeyehu A, Birhanu Z (2012) Institutional delivery service utilization in Munisa Woreda, South East Ethiopia: a community based cross-sectional study. BMC Pregnancy Childbirth 12: 105.

16. Abera M, Gebremariam A, Belachew T (2011) Predictors of safe delivery service utilization in arsi zone, South-East ethiopia. Ethiop J Health Sci 21: 95-106.

17. Yared M, Asnaketch M (2002) ORC Utilization of Maternal Health Care Services in Ethiopia. ORC Macro, Calverton, Maryland, USA.

18. Yanagisawa S, Oum S, Wakai S (2006) Determinants of skilled birth attendance in rural Cambodia. Trop Med Int Health 11: 238-251.

19. Nasreen HE, Leppard M, Al Mamun M, Billah M, Mistry SK, et al. (2012) Men's knowledge and awareness of maternal, neonatal and child health care in rural Bangladesh: a comparative cross sectional study. Reprod Health 9: 18.

20. Simkhada B, van Teijlingen ER, Porter M, Simkhada P (2006) Major problems and key issues in Maternal Health in Nepal. Kathmandu Univ Med J (KUMJ) 4: 258-263.

21. Rural Raya Alamata woreda health office, 2013.

22. Freweini, G/Hiwot (2009) Assessment of factors for safe delivery service utilization among women of childbearing age in Ephratanagidim District, Ethiopia. Addis Ababa University.

23. Lwelamira J, Safari J (2012) Choice of Place for Childbirth: Prevalence and Determinants of Health Facility Delivery among Women in Bahi District, Central Tanzania. Asian Journal of Medical Sciences 4: 105-112.

24. Jat TR, Ng N, San Sebastian M (2011) Factors affecting the use of maternal health services in Madhya Pradesh state of India: a multilevel analysis. Int J Equity Health 10: 59.

25. Ochako R, Fotso JC, Ikamari L, Khasakhala A (2011) Utilization of maternal health services among young women in Kenya: insights from the Kenya Demographic and Health Survey, 2003. BMC Pregnancy Childbirth 11: 1 .

26. Mengesha ZB, Biks GA, Ayele TA, Tessema GA, Koye DN (2013) Determinants of skilled attendance for delivery in Northwest Ethiopia: a community based nested case control study. BMC Public Health 13: 130.

27. Mpembeni RN, Killewo JZ, Leshabari MT, Massawe SN, Jahn A, et al. (2007) Use pattern of maternal health services and determinants of skilled care during delivery in Southern Tanzania: implications for achievement of MDG-5 targets. BMC Pregnancy Childbirth 7: 29. 
Citation: Tadese F, Ali A (2014) Determinants of Use of Skilled Birth Attendance among Mothers Who Gave Birth in the Past 12 months in Raya Alamata District, North East Ethiopia. Clinics Mother Child Health 11: 164. doi:10.4172/2090-7214.1000164

Page 9 of 9

28. Kabakyenga JK, Östergren PO, Turyakira E, Pettersson KO (2012) Influence of birth preparedness, decision-making on location of birth and assistance by skilled birth attendants among women in southwestern Uganda. PLoS One 7: e35747. 